\author{
Asian Journal of \\ Medical and Biological Research \\ ISSN 2411-4472 (Print) 2412-5571 (Online) \\ www.ebupress.com/journal/ajmbr
}

\title{
Article \\ Impact of type 2 Diabetes Mellitus for developing severe health complications in Bangladeshi population
}

\author{
Shabbir Ahmed ${ }^{1}$, Tasnim Ahmed ${ }^{1 *}$, Tarana Sharmin ${ }^{1}$ and Sharif Mohammad Ruhul Quddus ${ }^{2}$ \\ ${ }^{1}$ Department of Genetic Engineering and Biotechnology, University of Dhaka, Dhaka, Bangladesh \\ ${ }^{2}$ Department of Neurology, BIRDEM General Hospital, Dhaka, Bangladesh \\ *Corresponding author: Tasnim Ahmed, Science Complex building, University of Dhaka, Dhaka-1000, \\ Bangladesh. Phone: +8801749280114; E-mail: tasnim.ahmed@du.ac.bd
}

Received: 11 April 2017/Accepted: 07 May 2017/ Published: 29 June 2017

\begin{abstract}
Type 2 diabetes mellitus is one of the deadliest disease in Bangladesh as its complications are enormous and life threatening. This study demonstrates the prevalence of the complications of type 2 diabetes among the population of Bangladesh. Data of 1000 subjects admitted into BIRDEM General Hospital from May 2015 to April 2016 were taken into consideration. Significantly, it was found that $89 \%$ patients had fasting blood glucose (FBG) level greater than $7 \mathrm{mmol} / \mathrm{l}$ and $70.8 \%$ patients had glycosylated hemoglobin (HbA1c) level greater than $8 \%$. As a consequence, the total population were affected by diverse health complications including lung, liver, cardiovascular, kidney, brain, oral, eye, thyroid, hearing, skin, and so on. Males and females were suffered from these complications without biasedness.
\end{abstract}

Keywords: Type 2 diabetes; fasting blood glucose; glycosylated hemoglobin; complications

\section{Introduction}

Global prevalence of diabetes is increasing day by day. It was estimated that the prevalence of diabetes in 2000 was $2.8 \%$ and will be $4.4 \%$ in 2030 indicating that 366 million people will be affected by this disease in 2030 (Wild et al., 2004). Type 2 diabetes mellitus (T2DM) is most common among the other types and the highest increase of its occurrence is, however, predicted to appear in Asia (Wild et al., 2004). T2DM which was formally denoted as "adult onset diabetes" or "non-insulin dependent diabetes mellitus" (NIDDM), is the consequence of body's inability of using insulin. Long-term complications from this disease include lung, liver, cardiovascular, kidney, brain, oral, eye, foot, skin diseases, and hearing impairments which possess deleterious effect on the body. Lung diseases in diabetic patients include asthma, chronic obstructive pulmonary disease (COPD), pulmonary fibrosis, pneumonia, and tuberculosis (Ehrlich et al., 2010). The entire degree of liver complications is detected in diabetic patients. Liver condition deteriorates in aberrant homeostasis of blood glucose which eventually plays significant roles in developing cholelithiasis, hepatitis B and C, cirrhosis and non-alcoholic fatty liver disease (NAFLD)in diabetic patients (Tolman et al., 2007). Diabetes causes damage to the blood vessels and blocks the natural circulation of blood which affects heart normally known as cardiovascular disease (CVD). CVD including heart failure, cardiomyopathy, peripheral arterial disease (PAD), and coronary heart disease frequently observed in diabetic patients (Wilson, 1998). Nephropathy, microalbuminuria, proteinuria, kidney failure being the major types of kidney diseases are quite familiar in diabetic patients (Coresh et al., 2003). These diseases take several years to develop. Diabetic patients have the increased risks of developing brain diseases like stroke, and dementia (Beul, 1994; Ott et al., 1996). Another less frequent brain disease named Alzheimer's disease (AD) is closely related to diabetes (Li et al., 2015). Diabetic patients suffer from some common oral diseases like periodontitis, oral mucosal lesion (OML), and dental caries (Al-Maskari et al., 2011). Eye diseases including retinopathy, diabetic macular edema, cataract, 
and glaucoma are prevalent among diabetic patients and these diseases often lead to blindness (Moss et al., 1998).

Though T2DM is found responsible for a number of long-term health complications among the adult population, it is little known about their occurrence in Bangladeshi population. In this study, the current status of T2DM patients is detected and the prevalence of lung, liver, heart, kidney, brain, oral, eye, thyroid, hearing, skin and foot complications related to T2DM are measured. The role of gender in the manifestation of these complications is also investigated.

\section{Materials and Methods}

\subsection{Design}

The study was conducted among 1000 patients (500 males and 500 females) aged between 31-90 years who were attending the BIRDEM General Hospital under Bangladesh Institute of Research \& Rehabilitation in Diabetes, Endocrine and Metabolic Disorders (BIRDEM) from May 2015 to April 2016. BIRDEM is the leading diagnosis and treatment hospital of Bangladesh for diabetes. As a result the collected data are significant as enormous patients attend this medical organization for treatment of diabetes. All information including tests was used here considering the oral and written informed consent of the patients. In addition, the ethical issues of the hospital also maintained here. Disease profile and personal information of the patients related to the study were taken into consideration and written down in the questionnaire.

\subsection{Measurement of parameters}

Blood samples were collected from the patients for measuring fasting blood glucose (FBG) and glycosylated hemoglobin (HbA1c).FBG level was assessed using glucose oxidase and peroxidase method while HbA1c was evaluated by immunoturbidimetric inhibition method (Zander et al., 1984; Marks, 1996).

\subsection{Statistical analysis}

For statistical analysis, SPSS (SPSS Inc., Chicago, USA) and MS Excel 2016 Analysis ToolPak were used. Prevalence with confidence interval (CI) was measured where significance level was set at 95\%. Exact binomial value was used as the value of CI. Sample proportion of male and female was compared using z-test. For each characteristic of complications, $\mathrm{p}$-value and male to female ratio were calculated. The significance of the result was considered as $\mathrm{p}<0.05$.

\section{Results}

\subsection{Status of FBG and HbA1c and prevalence of the major complications}

Status of fasting blood glucose (FBG) and glycosylated hemoglobin (HbA1c) and prevalence of the major severe complications among T2DM patients and test results of comparing sample proportion between male and female patients were shown in Table 1. Among 1000 patients, 890 (89\%, CI=86.9-90.9) patients had FBG level greater than $7 \mathrm{mmol} / \mathrm{l}$ and $708(70.8 \%, \mathrm{CI}=67.9-73.6)$ patients had $\mathrm{HbA} 1 \mathrm{c}$ level greater than $8 \%$. As a result, $114(11.4 \%, \mathrm{CI}=9.5-13.5)$ patients were affected by lung diseases where $51(10.2 \%, \mathrm{CI}=7.7-13.2)$ patients were males and $63(12.6 \%, \mathrm{CI}=9.8-15.8)$ patients were females (Male: Female, $[\mathrm{M}: \mathrm{F}]=1: 1.23)$. In case of liver diseases, $246(24.6 \%, \mathrm{CI}=22-27.4)$ patients were affected where $125(25 \%, \mathrm{CI}=21.3-29)$ patients were males and $121(24.2 \%, \mathrm{CI}=20.5-28.2)$ patients were females $(\mathrm{M}: \mathrm{F}=1.03: 1) .145(14.5 \%, \mathrm{CI}=12.4-16.8)$ patients were affected by cardiovascular diseases where73 $(14.6 \%, \mathrm{CI}=11.6-18)$ and $72(14.4 \%, \mathrm{CI}=11.4-17.8)$ patients were males and females respectively (M:F=1.01:1). In case of kidney diseases, $117(11.7 \%, \mathrm{CI}=9.8-13.9)$ patients were affected where50 (10\%, CI=7.5-13) and $67(13.4 \%, \mathrm{CI}=10.5-16.7)$ patients were males and females respectively ( $\mathrm{M}: \mathrm{F}=1: 1.34)$. Brain diseases affected $86(8.6 \%, \mathrm{CI}=6.9-10.5)$ patients where48 (9.6\%, CI=7.2$12.5)$ and $38(7.6 \%, \mathrm{CI}=5.4-10.3)$ patients were males and females respectively $(\mathrm{M}: \mathrm{F}=1.26: 1) .80(8 \%, \mathrm{CI}=6.4-$ 9.9) patients, where $38(7.6 \%, \mathrm{CI}=5.4-10.3)$ were males and $42(8.4 \%, \mathrm{CI}=6.1-11.2)$ were females and affected by oral diseases $(\mathrm{M}: \mathrm{F}=1: 1.1) .64(6.4 \%, \mathrm{CI}=5-8.1)$ patients were affected by eye diseases where31 $(6.2 \%, \mathrm{CI}=4.3-$ $8.7)$ and $33(6.6 \%, \mathrm{CI}=4.6-9.1)$ were males and females respectively with a ratio of 1:1.06. In case of thyroid disorders, $30(3 \%, \mathrm{CI}=2-4.3)$ patients were affected where $14(2.8 \%, \mathrm{CI}=1.5-4.7)$ and $16(3.2 \%, \mathrm{CI}=1.8-5.1)$ patients were males and females respectively ( $\mathrm{M}: \mathrm{F}=1: 1.14)$. With respect to hearing impairment, 104 (10.4\%, $\mathrm{CI}=8.6-12.5)$ patients were affected where $33(6.6 \%, \mathrm{CI}=4.6-9.1)$ and $71(14.2 \%, \mathrm{CI}=11.3-17.6)$ patients were males and females respectively $(\mathrm{M}: \mathrm{F}=1: 2.15) .75(7.5 \%, \mathrm{CI}=5.9-9.3)$ patients where $52(10.4 \%, \mathrm{CI}=7.9-13.4)$ and $23(4.6 \%, \mathrm{CI}=2.9-6.8)$ patients were males and females respectively were found affected by skin diseases $(\mathrm{M}: \mathrm{F}=2.26: 1)$. In case of diabetic foot diseases, 93 (9.3\%, CI=7.6-11.3) patients consisting of 68 (13.6\%, $\mathrm{CI}=10.7-16.9)$ males and $25(5 \%, \mathrm{CI}=3.3-7.3)$ females $(\mathrm{M}: \mathrm{F}=2.72: 1)$ were affected. In comparisons of sample 
proportions between male and female patients, only in case of hearing impairment, skin diseases, and diabetic foot diseases, the test results showed significance at 95\% confidence interval $(\mathrm{p}<0.05)$.

\subsection{Prevalence of different subtype of complications}

Table 2 and Table 3 showed the prevalence of different subtype of lung, liver, cardiovascular, kidney, brain, oral, eye, thyroid disorders and test results of comparing sample proportion between male and female patients. In case of lung diseases, $29(2.9 \%, \mathrm{CI}=2-4.1), 35(3.5 \%, \mathrm{CI}=2.4-4.8), 17(1.7 \%, \mathrm{CI}=1-2.7), 11(1.1 \%, \mathrm{CI}=0.6-2)$, $19(1.9 \%, \mathrm{CI}=1.1-3)$, and $3(0.3 \%, \mathrm{CI}=0.1-0.9)$ patients were affected by asthma, chronic obstructive pulmonary disease (COPD), pulmonary fibrosis, pneumonia, tuberculosis and lung cancer respectively. In case of liver diseases, 75 (7.5\%, CI=5.9-9.3), 8(0.8\%, CI=0.3-1.6), 17(1.7\%, CI=1-2.7), $15(1.5 \%, \mathrm{CI}=0.8-2.5)$ and 144 $(14.4 \%, \mathrm{CI}=12.3-16.7)$ were affected by cholelithiasis, hepatitis $\mathrm{B}$, hepatitis $\mathrm{C}$, cirrhosis, and non-alcoholic fatty liver disease (NAFLD) respectively. In aspect of cardiovascular diseases, 79(7.9\%, CI=6.3-9.7), 9(0.9\%, $\mathrm{CI}=0.4-1.7), 38$ (3.8\%, $\mathrm{CI}=2.7-5.2)$ and 23 (2.3\%, $\mathrm{CI}=1.5-3.4)$ patients had heart failure, cardiomyopathy, peripheral arterial disease and coronary heart disease respectively. For kidney diseases, $51(5.1 \%, \mathrm{CI}=3.8-6.7)$, $24(2.4 \%, \mathrm{CI}=1.5-3.6), 13(1.3 \%, \mathrm{CI}=0.7-2.2)$ and 29 (2.9\%, CI=2-4.1) patients had nephropathy, micro albuminuria, proteinuria, and chronic kidney disease respectively. In case of brain diseases, 69(6.9\%, CI=5.48.7), $15(1.5 \%, \mathrm{CI}=0.8-2.5)$ and $3(0.3 \%, \mathrm{CI}=0.1-0.9)$ patients were found affected by stroke, dementia, and Alzheimer's diseases respectively. In case of oral diseases, 31(3.1\%, CI=2.1-4.4), $29(2.9 \%, \mathrm{CI}=2-4.1)$ and 22 (2.2\%, CI=1.4-3.3) patients were affected by periodontitis, oral mucosal lesion, and dental caries respectively. In case of eye diseases, 25 (2.5\%, CI=1.6-3.7), 11(1.1\%, CI=0.6-2), 17(1.7\%, CI=1-2.7) and $11(1.1 \%, \mathrm{CI}=0.6-$ 2) patients had retinopathy, diabetic macular edema, cataract, and glaucoma respectively. For thyroid disorders, $21(2.1 \%, \mathrm{CI}=1.3-3.2)$ patients were affected by hypothyroidism and $9(0.9 \%, \mathrm{CI}=0.4-1.7)$ patients were affected by hyperthyroidism. While comparing sample proportion between male and female patients, in case of hepatitis $C$ and cataract showed significance at $95 \%$ confidence interval $(p<0.05)$.

Table 1. Status of FBG and HbA1c and prevalence of the major complications among type 2 diabetic patients.

\begin{tabular}{|c|c|c|c|c|c|c|c|c|}
\hline \multirow[t]{2}{*}{ Complications } & \multicolumn{2}{|c|}{ Total $(n=1000)$} & \multicolumn{2}{|c|}{ Male $(\mathbf{n}=500)$} & \multicolumn{2}{|c|}{ Female $(n=500)$} & \multirow[t]{2}{*}{ Ratio $^{\mathbf{b}}$} & \multirow[t]{2}{*}{ p-value ${ }^{a}$} \\
\hline & Affected & $\begin{array}{l}\text { Prevalence (\%) } \\
(\mathrm{CI})^{\mathrm{a}}\end{array}$ & Affected & $\begin{array}{l}\text { Prevalence (\%) } \\
(\mathrm{CI})^{\mathrm{a}}\end{array}$ & Affected & $\begin{array}{l}\text { Prevalence (\%) } \\
(\mathrm{CI})^{\mathrm{a}}\end{array}$ & & \\
\hline FBG>7 mmol/l & 890 & $89(86.9-90.9)$ & 432 & $86.4(83.1-89.3)$ & 458 & $91.6(88.8-93.9)$ & $1: 1.06$ & $0.01 *$ \\
\hline $\mathrm{HbA} 1 \mathrm{c} \geq 8 \%$ & 708 & $70.8(67.9-73.6)$ & 358 & $71.6(67.4-75.5)$ & 350 & $70(65.8-74)$ & $1.02: 1$ & 0.6 \\
\hline $\begin{array}{l}\text { Lung } \\
\text { diseases }\end{array}$ & 114 & $11.4(9.5-13.5)$ & 51 & $10.2(7.7-13.2)$ & 63 & $12.6(9.8-15.8)$ & $1: 1.23$ & 0.2 \\
\hline $\begin{array}{l}\text { Liver } \\
\text { diseases }\end{array}$ & 246 & $24.6(22-27.4)$ & 125 & $25(21.3-29)$ & 121 & $24.2(20.5-28.2)$ & $1.03: 1$ & 0.3 \\
\hline $\begin{array}{l}\text { Cardiovascular } \\
\text { diseases }\end{array}$ & 145 & $14.5(12.4-16.8)$ & 73 & $14.6(11.6-18)$ & 72 & $14.4(11.4-17.8)$ & $1.01: 1$ & 0.9 \\
\hline $\begin{array}{l}\text { Kidney } \\
\text { diseases }\end{array}$ & 117 & $11.7(9.8-13.9)$ & 50 & $10(7.5-13)$ & 67 & $13.4(10.5-16.7)$ & $1: 1.34$ & 0.1 \\
\hline $\begin{array}{l}\text { Brain } \\
\text { diseases }\end{array}$ & 86 & $8.6(6.9-10.5)$ & 48 & $9.6(7.2-12.5)$ & 38 & $7.6(5.4-10.3)$ & $1.26: 1$ & 0.3 \\
\hline $\begin{array}{l}\text { Oral } \\
\text { diseases }\end{array}$ & 80 & $8(6.4-9.9)$ & 38 & $7.6(5.4-10.3)$ & 42 & $8.4(6.1-11.2)$ & $1: 1.1$ & 0.6 \\
\hline Eye & 64 & $6.4(5-8.1)$ & 31 & $6.2(4.3-8.7)$ & 33 & $6.6(4.6-9.1)$ & $1: 1.06$ & 0.8 \\
\hline $\begin{array}{l}\text { Thyroid } \\
\text { disorders }\end{array}$ & 30 & $3(2-4.3)$ & 14 & $2.8(1.5-4.7)$ & 16 & $3.2(1.8-5.1)$ & $1: 1.14$ & 0.7 \\
\hline $\begin{array}{l}\text { Hearing } \\
\text { impairment }\end{array}$ & 104 & $10.4(8.6-12.5)$ & 33 & $6.6(4.6-9.1)$ & 71 & $14.2(11.3-17.6)$ & $1: 2.15$ & $<0.0001 *$ \\
\hline $\begin{array}{l}\text { Skin } \\
\text { diseases }\end{array}$ & 75 & $7.5(5.9-9.3)$ & 52 & $10.4(7.9-13.4)$ & 23 & $4.6(2.9-6.8)$ & $2.26: 1$ & $0.0005^{*}$ \\
\hline $\begin{array}{l}\text { Diabetic foot } \\
\text { diseases }\end{array}$ & 93 & $9.3(7.6-11.3)$ & 68 & 13.6(10.7-16.9) & 25 & $5(3.3-7.3)$ & $2.72: 1$ & $<0.0001 *$ \\
\hline
\end{tabular}

$\mathrm{a}=95 \%$ confidence interval; $\mathrm{b}=$ male: female; $*$ =significant at $95 \%$ confidence interval 
Asian J. Med. Biol. Res. 2017, 3 (2)

Table 2. Prevalence of different subtype of lung, liver, cardiovascular and kidney diseases.

\begin{tabular}{|c|c|c|c|c|c|c|c|c|}
\hline \multirow[t]{2}{*}{ Complications } & \multicolumn{2}{|c|}{ Total $(n=1000)$} & \multicolumn{2}{|c|}{ Male $(n=500)$} & \multicolumn{2}{|c|}{ Female $(n=500)$} & \multirow[t]{2}{*}{ Ratio $^{b}$} & \multirow[t]{2}{*}{ p-value ${ }^{\mathrm{a}}$} \\
\hline & Affected & $\begin{array}{l}\text { Prevalence } \\
(\%)(C I)^{a}\end{array}$ & Affected & $\begin{array}{l}\text { Prevalence } \\
(\%)(C I)^{a}\end{array}$ & Affected & $\begin{array}{l}\text { Prevalence } \\
(\%)(C I)^{a}\end{array}$ & & \\
\hline \multicolumn{9}{|c|}{ Lung diseases } \\
\hline Asthma & 29 & $2.9(2-4.1)$ & 12 & $2.4(1.2-4.2)$ & 17 & $3.4(2-5.4)$ & $1: 1.42$ & 0.3 \\
\hline COPD & 35 & $3.5(2.4-4.8)$ & 14 & $2.8(1.5-4.7)$ & 21 & $4.2(2.6-6.3)$ & $1: 1.5$ & 0.2 \\
\hline Pulmonary fibrosis & 17 & $1.7(1-2.7)$ & 9 & $1.8(0.8-3.4)$ & 8 & $1.6(0.7-3.1)$ & $1.12: 1$ & 0.8 \\
\hline Pneumonia & 11 & $1.1(0.6-2)$ & 4 & $0.8(0.02-2)$ & 7 & $1.4(0.6-2.9)$ & $1: 1.75$ & 0.4 \\
\hline Tuberculosis & 19 & $1.9(1.1-3)$ & 10 & $2(1-3.6)$ & 9 & $1.8(0.8-3.4)$ & $1.11: 1$ & 0.2 \\
\hline Lung cancer & 3 & $0.3(0.1-0.9)$ & 2 & $0.4(0-1.4)$ & 1 & $0.2(0-1.1)$ & $2: 1$ & 0.6 \\
\hline \multicolumn{9}{|c|}{ Liver diseases } \\
\hline Cholelithiasis & 75 & $7.5(5.9-9.3)$ & 32 & $6.4(4.4-8.9)$ & 43 & $8.6(6.3-11.4)$ & $1: 1.34$ & 0.2 \\
\hline Hepatitis B & 8 & $0.8(0.3-1.6)$ & 5 & $1(0.3-2.3)$ & 3 & $0.6(0.1-1.7)$ & $1.67: 1$ & 0.5 \\
\hline Hepatitis C & 17 & $1.7(1-2.7)$ & 4 & $0.8(0.2-2)$ & 13 & $2.6(1.4-4.4)$ & $1: 3.25$ & $0.03 *$ \\
\hline Cirrhosis & 15 & $1.5(0.8-2.5)$ & 10 & $2(1-3.6)$ & 5 & $1(0.3-2.3)$ & $2: 1$ & 0.2 \\
\hline NAFLD & 144 & $14.4(12.3-16.7)$ & 79 & $15.8(12.7-19.3)$ & 65 & $13(10.2-16.3)$ & $1.21: 1$ & 0.2 \\
\hline \multicolumn{9}{|c|}{ Cardiovascular diseases } \\
\hline Heart failure & 79 & $7.9(6.3-9.7)$ & 43 & $8.6(6.3-11.4)$ & 36 & $7.2(5.1-9.8)$ & 1.19:1 & 0.4 \\
\hline Cardiomyopathy & 9 & $0.9(0.4-1.7)$ & 3 & $0.6(0.1-1.7)$ & 6 & $1.2(0.4-2.6)$ & $1: 2$ & 0.3 \\
\hline $\begin{array}{l}\text { Peripheral arterial } \\
\text { disease }\end{array}$ & 38 & $3.8(2.7-5.2)$ & 16 & $3.2(1.8-5.1)$ & 22 & $4.4(2.8-6.6)$ & $1: 1.37$ & 0.3 \\
\hline $\begin{array}{l}\text { Coronary heart } \\
\text { disease }\end{array}$ & 23 & $2.3(1.5-3.4)$ & 12 & $2.4(1.2-4.2)$ & 11 & $2.2(1.1-3.9)$ & 1.09:1 & 0.8 \\
\hline \multicolumn{9}{|c|}{ Kidney diseases } \\
\hline Nephropathy & 51 & $5.1(3.8-6.7)$ & 22 & $4.4(2.8-6.6)$ & 29 & $5.8(3.9-8.2)$ & $1: 1.32$ & 0.3 \\
\hline Microalbuminuria & 24 & $2.4(1.5-3.6)$ & 11 & $2.2(1.1-3.9)$ & 13 & $2.6(1.4-4.4)$ & $1: 1.18$ & 0.7 \\
\hline Proteinuria & 13 & $1.3(0.7-2.2)$ & 5 & $1(0.3-2)$ & 8 & $1.6(0.6-3.1)$ & $1: 1.6$ & 0.4 \\
\hline $\begin{array}{l}\text { Chronic kidney } \\
\text { disease }\end{array}$ & 29 & $2.9(2-4.1)$ & 12 & $2.4(1.2-4.2)$ & 17 & $3.4(2-5.4)$ & $1: 1.42$ & 0.3 \\
\hline
\end{tabular}

$\mathrm{a}=95 \%$ confidence interval; $\mathrm{b}=$ male: female; $*=$ significant at $95 \%$ confidence interval

Table 3. Prevalence of different subtype of brain, oral, eye, thyroid disorders.

\begin{tabular}{|c|c|c|c|c|c|c|c|c|}
\hline \multirow[t]{2}{*}{ Complications } & \multicolumn{2}{|c|}{ Total $(n=1000)$} & \multicolumn{2}{|c|}{ Male $(n=500)$} & \multicolumn{2}{|c|}{ Female $(n=500)$} & \multirow[t]{2}{*}{ Ratio $^{b}$} & \multirow[t]{2}{*}{ p-value } \\
\hline & Affected & $\begin{array}{l}\text { Prevalence } \\
(\%)(C I)^{a}\end{array}$ & Affected & $\begin{array}{l}\text { Prevalence } \\
(\%)(C I)^{a}\end{array}$ & Affected & $\begin{array}{l}\text { Prevalence } \\
(\%)(C I)^{a}\end{array}$ & & \\
\hline \multicolumn{9}{|c|}{ Brain diseases } \\
\hline Stroke & 69 & $6.9(5.4-8.7)$ & 39 & $7.8(5.6-10.5)$ & 30 & $6(4.1-8.5)$ & $1.3: 1$ & 0.3 \\
\hline Dementia & 15 & $1.5(0.8-2.5)$ & 8 & $1.6(0.6-3.1)$ & 7 & $1.4(0.5-2.9)$ & $1.14: 1$ & 0.8 \\
\hline $\begin{array}{l}\text { Alzheimer's } \\
\text { disease }\end{array}$ & 3 & $0.3(0.1-0.9)$ & 2 & $0.4(0.05-1.4)$ & 1 & $0.2(0.005-1.1)$ & $2: 1$ & 0.6 \\
\hline \multicolumn{9}{|c|}{ Oral diseases } \\
\hline Periodontitis & 31 & $3.1(2.1-4.4)$ & 12 & $2.4(1.2-4.2)$ & 19 & $3.8(2.3-5.9)$ & $1: 1.58$ & 0.2 \\
\hline $\begin{array}{l}\text { Oral mucosal } \\
\text { lesion }\end{array}$ & 29 & $2.9(2-4.1)$ & 17 & $3.4(2-5.4)$ & 12 & $2.4(1.2-4.2)$ & $1.41: 1$ & 0.3 \\
\hline Dental caries & 22 & $2.2(1.4-3.3)$ & 11 & $2.2(1.1-3.9)$ & 11 & $2.2(1.1-3.9)$ & $1: 1$ & 1 \\
\hline \multicolumn{9}{|c|}{ Eye diseases } \\
\hline Retinopathy & 25 & $2.5(1.6-3.7)$ & 9 & $1.8(0.8-3.4)$ & 16 & $3.2(1.8-5.1)$ & $1: 1.78$ & 0.2 \\
\hline $\begin{array}{l}\text { Diabetic macular } \\
\text { edema }\end{array}$ & 11 & $1.1(0.6-2)$ & 3 & $0.6(0.1-1.7)$ & 8 & $1.6(0.7-3.1)$ & $1: 2.67$ & 0.1 \\
\hline Cataract & 17 & $1.7(1-2.7)$ & 13 & $2.6(1.4-4.4)$ & 4 & $0.8(0.2-2)$ & $3.25: 1$ & $0.03 *$ \\
\hline Glaucoma & 11 & $1.1(0.6-2)$ & 6 & $1.2(0.4-2.6)$ & 5 & $1(0.3-2.3)$ & $1.2: 1$ & 0.8 \\
\hline \multicolumn{9}{|c|}{ Thyroid disorders } \\
\hline Hypothyroidism & 21 & $2.1(1.3-3.2)$ & 10 & $2(1-3.6)$ & 11 & $2.2(1.1-3.9)$ & $1: 1.1$ & 0.8 \\
\hline Hyperthyroidism & 9 & $0.9(0.4-1.7)$ & 4 & $0.8(0.2-2)$ & 5 & $1(0.3-2.3)$ & $1: 1.25$ & 0.7 \\
\hline
\end{tabular}

$a=95 \%$ confidence interval; $b=$ male: female; $*$ =significant at $95 \%$ confidence interval 


\section{Discussion}

T2DM simultaneously influences in developing a number of metabolic disorders which eventually result in various death threatening complications. It is often observed that many patients develop more than one complication at a time. Very limited studies have been carried out about the complications related to T2DM in Bangladesh. In fact, this is the first study elucidating the overall scenarios of these complications among the diabetic patients in this particular area. Approximately 11.4\%, 24.6\%, 14.5\%, 11.7\%, 8.6\%, 8\%, 6.4\%, 3\%, $10.4 \%, 7.5 \%$, and $9.3 \%$ of the total population were affected by lung, liver, cardiovascular, kidney, brain, oral, eye, thyroid, hearing, skin, and foot diseases respectively.

In this study, among the $11.4 \%$ of lung disease patients, asthma, COPD, pulmonary fibrosis, pneumonia, tuberculosis, and lung cancer prevalence are $2.9 \%, 3.5 \%, 1.7 \%, 1.1 \%, 1.9 \%$, and $0.3 \%$ respectively. Female patients are affected more by asthma, COPD, and pneumonia. Liver diseases have the prevalence of $24.6 \%$ which consists of cholelithiasis (7.5\%), hepatitis B (0.8\%), hepatitis C(1.7\%), cirrhosis (1.5\%), and NAFLD (14.4\%).Liver diseases are highly prevalent than the other type of diseases and male patients have the slightly higher risk of developing hepatitis B, liver cirrhosis, and NAFLD. Hepatitis C is significantly more prevalent among female patients $(\mathrm{p}<0.05)$.The prevalence of cardiovascular diseases is $14.5 \%$ which contains heart failure $(7.9 \%)$, cardiomyopathy $(0.9 \%)$, peripheral arterial disease (3.8\%), and coronary heart disease $(2.3 \%)$. Male and female patients are quite equally affected by these diseases but the risk of having heart failure is found higher in male patients. Kidney diseases which consist of nephropathy $(5.1 \%)$, microalbuminuria $(2.4 \%)$, proteinuria $(1.3 \%)$, and chronic kidney disease $(2.9 \%)$ have the prevalence of $11.7 \%$. In this case, female patients have the higher risk of developing these complications. A previous study showed that chronic kidney disease was highly prevalent in T2DMpatients in the urban areas of Bangladesh (Anand et al., 2014). The prevalence of brain disease is $8.6 \%$ where stroke, dementia, and Alzheimer's disease have the prevalence of $6.9 \%, 1.5 \%$, and $0.3 \%$ respectively. Male patients develop these diseases more than the female patients. Oral diseases have the prevalence of $8 \%$ where periodontitis, oral mucosal lesion, and dental caries have the prevalence of 3.1\%, $2.9 \%$ and $2.2 \%$ respectively. Periodontitis has the higher prevalence in female patients while oral mucosal lesion is found high in male patients. A previous study showed that the dental diseases were significantly prevalent among the T2DM patients of this area (Choudhury et al., 2016). Eye diseases have the prevalence of $6.4 \%$ where retinopathy, diabetic macular edema, cataract, and glaucoma have the prevalence of $2.5 \%, 1.1 \%, 1.7 \%$, and $1.1 \%$ respectively. Retinopathy and diabetic macular edema have the higher prevalence in female patients. Cataract is significantly higher in male patients $(\mathrm{p}<0.05)$. The prevalence of diabetic retinopathy was found high (4.1\%) in a previous study (Ahmed et al., 2012). The prevalence of thyroid disorder is $3 \%$ which is composed of hypothyroidism $(2.1 \%)$ and hyperthyroidism $(0.9 \%)$.The occurrence of these diseases are also almost equal among male and female patients. In a previous study, the prevalence of thyroid dysfunction among T2DM patients was found $10 \%$ in an urban diabetic hospital of Bangladesh (Moslem et al., 2015). The prevalence of hearing impairment, skin diseases, and diabetic foot diseases are $10.4 \%, 7.5 \%$ and $9.3 \%$ respectively. The prevalence of hearing impairment is significantly higher in female patients while skin diseases and diabetic foot diseases are significantly higher in male patients $(\mathrm{p}<0.05)$.

The complications of T2DM develop gradually and to control these complications, blood sugar and HbA1c should be monitored frequently. T2DM can be managed by following healthy lifestyle such as eating foods which are higher in fiber and lower in calories, taking regular physical activity and carefully monitoring the blood glucose level. Some frequently reported risk factors of T2DM include geography, ethnicity, gender, family history of having this disease, prediabetes, gestational diabetes, overweight, physical inactivity, age, poor eating habits etc. These should be checked. Though the study was performed with great care, there were some limitations which could not easily be avoided. Some patients were under medications and the effects of such medications in altering the level of FBG and HbA1c were not clearly known.

\section{Conclusions}

The current study signifies some sound and profound findings. Firstly, the current status of T2DM and its complications among the population of Bangladesh are depicted. Utmost seriousness is given to get the whole scenarios of these complications. Secondly, the role of gender in developing these complications is detected and in some cases, it is observed that gender plays a significant role. This study may facilitate in acquiring the overview of T2DM disease, its complications and provide support in developing improved strategies to manage, control and prevent these complications. 


\section{Acknowledgments}

The authors would like to thank all the participants of the study for their important contributions. Authors are also indebted to BIRDEM General Hospital for providing great support for the study.

\section{Conflicts of interest}

None to declare.

\section{References}

Ahmed KR, MN Karim, B Bhowmik, SH Habib, MS Bukht, L Ali and A Hussain, 2012. Incidence of diabetic retinopathy in Bangladesh: a 15-year follow-up study. J. Diabetes, 4: 386-391.

Al-Maskari AY, MYAl-Maskari and SAl-Sudairy, 2011. Oral Manifestations and Complications of Diabetes Mellitus: A review. Sultan Qaboos Univ. Med. J., 11: 179-186.

Anand S, MA Khanam, J Saquib, N Saquib, T Ahmed, DS Alam, MR Cullen, M Barry and GM Chertow, 2014. High prevalence of chronic kidney disease in a community survey of urban Bangladeshis: a cross-sectional study. Global Health, 10: 9.

Beul DSH, 1994. Stroke in the Diabetic Patient. Diabetes Care, 17: 213-219.

Choudhury AR, KN Choudhury andSMS Islam,2016. Relationship of dental diseases with coronary artery diseases and diabetes in Bangladesh. Cardiovasc. Diagn. Ther., 6: 131-7.

Coresh J, BCAstor, T Greene, G Eknoyan and AS Levey, 2003. Prevalence of chronic kidney disease and decreased kidney function in the adult US population: Third National Health and Nutrition Examination Survey. Am. J. Kidney Dis., 41: 1-12.

Ehrlich SF, CP Quesenberry,VD Jr, SK Eeden, J Shan and A Ferrara, 2010. Patients diagnosed with diabetes are at increased risk for asthma, chronic obstructive pulmonary disease, pulmonary fibrosis, and pneumonia but not lung cancer. Diabetes Care, 33: 55-60.

Li X, D Song and SX Leng, 2015. Link between type 2 diabetes and Alzheimer's disease: from epidemiology to mechanism and treatment. Clin. Interv. Aging, 10: 549-560.

Marks V, 1996. An improved glucose-oxidase method for determini.g blood, C.S.F. and urine glucose levels. Clin. Chim. Acta., 251: 19-24.

Moslem F, TS Bithi and A Biswas, 2015. Prevalence of Thyroid Dysfunction Among Type-2 Diabetes Patients in an Urban Diabetes Hospital, Bangladesh. Open Sci. Jour. of Clin. Med., 3: 98-102.

Moss SE, R Klein and BE Klein, 1998. The 14-year incidence of visual loss in a diabetic population. Ophthalmology, 105: 998-1003.

Ott A, RP Stolk, A Hofman, FV Harskamp, DE Grobbee and MM Breteler, 1996. Association of diabetes mellitus and dementia: the Rotterdam Study. Diabetologia, 39: 1392-1397.

Tolman KG, V Fonseca, A Dalpiaz and MH Tan, 2007. Spectrum of Liver Disease in Type 2 Diabetes and Management of Patients With Diabetes and Liver Disease. Diabetes Care, 30: 734-743.

S Wild, G Roglic, A Green, R Sicree and H King, 2004. Global prevalence of diabetes: estimates for the year 2000 and projections for 2030. Diabetes Care, 27: 1047-1053.

Wilson PW, 1998. Diabetes mellitus and coronary heart disease. Am. J. Kidney Dis., 32: S89-100.

Zander R, W Lang and HU Wolf, 1984. Alkaline haematin D-575, a new tool for the determination of haemoglobin as an alternative to the cyanhaemiglobin method. I. Description of the method. Clin. Chim. Acta, 136: 83-93. 